\title{
Avaliação da contaminação de águas subterrâneas e dos riscos associados a estes usos em uma microbacia urbana em Campina Grande-PB
}

\author{
Assessment of groundwater contamination and the risks associated with these uses in an urban \\ microbasin in Campina Grande-PB \\ Evaluación de la contaminación de las aguas subterráneas y los riesgos asociados a estos usos en \\ una microcuenca urbana en Campina Grande-PB
}

Recebido: 02/09/2021 | Revisado: 10/09/2021 | Aceito: 26/10/2021 | Publicado: 29/10/2021

Rayssa de Lourdes Carvalho Marinho do Rêgo Catão
ORCID: https://orcid.org/0000-0002-4134-0373
Universidade Federal de Campina Grande, Brasil
E-mail: rayssacatao@ @mail.com
Rui de Oliveira
ORCID: https://orcid.org/0000-0002-1972-9809
Universidade Estadual da Paraíba
E-mail: ruideo@gmail.com
Patrícia Hermínio Cunha Feitosa
ORCID: https://orcid.org/0000-0001-6937-0817
Universidade Federal de Campina Grande, Brasil
phcfeotpsa@ outlook.com
Andréa Carla Lima Rodrigues
ORCID: https://orcid.org/0000-0002-4764-0430
Universidade Federal de Campina Grande, Brasil
E-mail: andrea.carla@ @rofessor.ufcg.edu.br
Carla Isoneide Araujo da Silva
ORCID: https://orcid.org/0000-0002-2723-1277
Universidade Federal de Campina Grande, Brasil
E-mail: carlasilva.esa@gmail.com
Ewerton Braúllio Nascimento Bezerra
ORCID: https://orcid.org/0000-0003-1742-8137
Universidade Estadual da Paraíba, Brasil
E-mail: ewertonbraullio@ hotmail.com
Wênio Vasconcelos Catão
ORCID: https://orcid.org/0000-0002-3474-0272
Universidade Estácio de Sá, Brasil
E-mail: wenioct@gmail.com
ORCID: https://orcid.org/0000-0003-1763-7721
Universidade Federal de Campina Grande, Brasil
E-mail: mteresag1308@gmail.com

\begin{abstract}
Resumo
Esse trabalho objetivou avaliar a contaminação das águas subterrâneas em duas microbacias urbanas em Campina Grande-PB, enfatizando o risco associado ao uso dessas águas. Os dados foram coletados de fevereiro a agosto de 2017. Neste período, foi identificado pontos de contaminação na área de estudo e aplicado um questionário para avaliar os usos da água subterrânea. Também foram analisados indicadores físico-químicos e microbiológicos para a avaliação da qualidade dessas águas. De acordo com os resultados, haviam pontos de contaminação próximo aos poços e o uso preponderante identificado foi a limpeza de ambientes, porém 1\% ingeriam essa água. Os dados obtidos, indicaram que havia contaminação por cloreto, fluoreto, E. Coli e coliformes totais, sendo imprópria para a ingestão humana. Caso haja a ingestão dessas águas, os usuários estarão sujeitos ao risco de contrair doenças como fluorose dentária e esquelética, além de complicações como alta na pressão arterial e pedras nos rins.
\end{abstract}

Palavras-chave: Águas subterrâneas urbanas; Poço tubular; Usos de águas subterrâneas; Padrões de potabilidade.

\begin{abstract}
This work aimed to evaluate the contamination of groundwater in two urban micro- basins in Campina Grande-PB, emphasizing the risk associated with the use of these waters. Data were collected from February to August 2017. During this period, points of contamination in the study area were identified and a questionnaire was applied to assess the uses of groundwater. Physical-chemical and microbiological indicators were also analyzed to assess the quality of
\end{abstract}


these waters. According to the results, there were points of contamination near the wells and the predominant use identified was cleaning environments, however $1 \%$ ingested this water. The data obtained indicated that there was contamination by chloride, fluoride, E. Coli and total coliforms, being unsuitable for human ingestion. If these waters are ingested, users will be subject to the risk of contracting diseases such as dental and skeletal fluorosis, as well as complications such as high blood pressure and kidney stones.

Keywords: Urban groundwaters; Tubular wells; Uses of groundwater; Potability standards.

\section{Resumen}

Este estudio tuvo como objetivo evaluar la contaminación de aguas subterráneas en dos microcuencas urbanas en Campina Grande-PB, enfatizando el riesgo asociado con el uso de estas aguas. Los datos se recolectaron de febrero a agosto de 2017. Durante este período, se identificaron puntos de contaminación en el área de estudio y se aplicó un cuestionario para evaluar los usos de las aguas subterráneas. También se analizaron indicadores físico-químicos y microbiológicos para evaluar la calidad de estas aguas. Según los resultados, existían puntos de contaminación cerca de los pozos y el uso predominante identificado fue la limpieza de ambientes, pero el 1\% ingirió esta agua. Los datos obtenidos indicaron que existía contaminación por cloruros, flúor, E. Coli y coliformes totales, siendo inadecuados para la ingestión humana. Si se ingieren estas aguas, los usuarios estarán sujetos al riesgo de contraer enfermedades como la fluorosis dental y esquelética, así como complicaciones como hipertensión arterial y cálculos renales.

Palabras clave: Agua subterránea urbana; Pozo tubular; Usos de aguas subterráneas; Normas de consumo.

\section{Introdução}

A água é um recurso natural essencial para a manutenção da vida na Terra. Segundo a Organização Mundial de Saúde, até o ano 2025, metade da população mundial viverá em áreas de escassez hídrica, tornando cada vez mais difícil o acesso à água (WHO, 2015).

Para "amortecer" os impactos negativos gerados pela escassez hídrica em todo o mundo, o uso de água subterrânea, é uma fonte bastante utilizada, especialmente em regiões áridas, onde o acesso à água doce é limitado (UNESCO, 2014; Karim et.al.,2018) Estima-se que o Brasil obtém cerca de $12 \%$ à $16 \%$ da água doce do mundo, as quais estão distribuídas em fontes superficiais e subterrâneas (Aith, 2015). No entanto, vários locais do país ainda sofrem com escassez hídrica, especialmente em regiões semiáridas.

A utilização de águas subterrâneas no Nordeste brasileiro localizado no semiarido, é de forma intensa, concentrando cerca de 52,2 \% (57.235 poços) das perfurações de poços tubulares do país, ainda que, represente menos de $1 / 5$ da extensão territorial nacional, tornando- se evidente assim, a carência do acesso a água por essa população (IBGE, 2018; CPRM, 2018). Todavia, a água subterrânea é vulnerável à poluição, em virtude da exposição a processos como a urbanização, o desenvolvimento industrial, as atividades agrícolas e de mineração (Salgado, 2016). Cerca de 48,2\% das residências situadas no Nordeste brasileiro, ainda despejam seu esgoto em fossas, permitindo a infiltração no solo e a contaminação do meio subterrâneo (IBGE, 2010). Essa contaminação decorrente da ação antrópica, principalmente em zonas urbanas, ocorre de forma silenciosa e bastante lenta, mas podem tomar grandes proporções em relação à saúde pública, caso a população faça o uso inadequado da água subterrânea.

Na cidade de Campina Grande-PB inserida na região nordeste deste país, os volumes das águas subterrâneas são espacialmente variáveis e podem sofrer influência na qualidade devido a hidrogeológica local, os aquíferos cristalinos, como consequência do intemperismo das rochas em contato com a água (Robins, 2002; Silva et. al, 2004). Porém, apesar de todos esses fatos adversos, em 2016 após o início de um racionamento de água na cidade, houve um aumento de $400 \%$ no número de perfurações de poços tubulares, proporcionando uma extração sem controle qualitativo e quantitativo de água subterrânea (Grisi, 2016).

Desta forma, a pesquisa que fundamentou este trabalho objetivou avaliar a contaminação de águas subterrâneas e os riscos associados aos seus usos em microbacias urbanas na cidade de Campina Grande-PB. 


\section{Metodologia}

A área de estudo está localizada na sede do município de Campina Grande - PB, a $7^{\circ} 13^{\prime} 11^{\prime \prime}$ de latitude Sul e a 3552’31” de longitude Oeste, como ilustrado na Figura 1 (IBGE, 2010).

Figura 1: Localização do município de Campina Grande-PB.

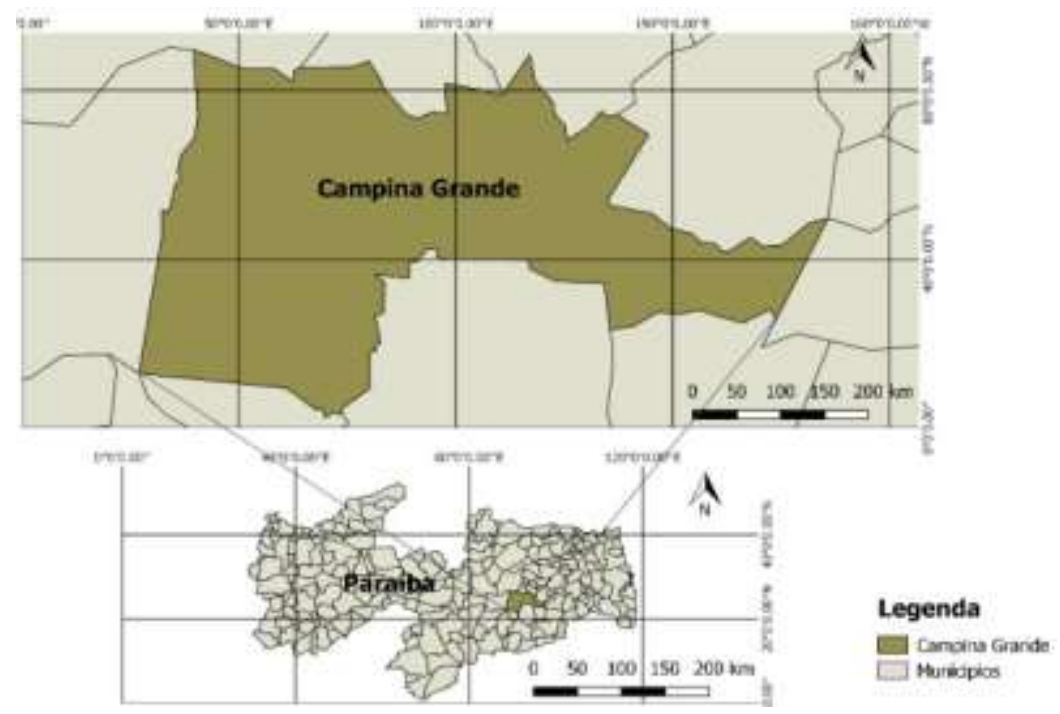

Fonte: Autoria própria.

Geologicamente, a região compreende um grande núcleo cristalino isolado, atingindo altitudes da ordem de $1.000 \mathrm{~m}$. O clima é semiárido quente, sendo a precipitação média 800 mm/ano.

Os indicadores avaliados nesta pesquisa foram selecionados com base em dez artigos científicos recentes (Oliveira et al., 2013; Bastos et al., 2012; Santos et al., 2014; Rodrigues et al., 2014; Razzolini et al., 2010; Sreedevi et al., 2006; Sotomayor et al., 2013; Lisbôa et al., 2016; Daneluz et al., 2015; Coelho et al., 2017), sobre a análise de águas de poços próximos a pontos de contaminação.

Foram escolhidos doze indicadores de qualidade de água a serem determinados conforme os procedimentos padrões (Tabela 1) descritos no Standard methods for the examination of water and wastewater (APHA, AWWA, WPCF, 2012).

Tabela 1: Indicadores e métodos utilizados na pesquisa.

\begin{tabular}{ll}
\hline Indicador & Método utilizado \\
\hline Temperatura & Termômetro de filamento de mercúrio \\
\hline $\mathrm{pH}$ & Potenciométrico \\
\hline Turbidez & Nefelométrico \\
\hline Condutividade elétrica & Potenciométrico \\
\hline Fluoreto & Colorimétrico SPADNS \\
\hline Cloreto & Argentométrico \\
\hline Nitrato & Coluna de cádmio \\
\hline Dureza total & Titulométrico do EDTA \\
\hline Sólidos totais dissolvidos & Gravimétrico \\
\hline Ferro & Colorimétrico da fenantrolina \\
\hline Coliformes totais & Substrato cromogênico \\
\hline Escherichia coli & Substrato cromogênico
\end{tabular}

Fonte: Autoria própria. 
Os pontos de coleta estavam inseridos em duas microbacias urbanas, com uso e ocupação do solo residencial, comercial e de serviços, com alta taxa de ocupação. Fora os efeitos de urbanização da área, a fronteira entre as duas microbacias, localizava-se um açude com águas eutrofizadas e um canal de drenagem de águas pluviais contaminado por lançamento de águas residuárias, sendo considerados para está pesquisa, como pontos de contaminação no meio subterrâneo (Torquato 2016).

Outro fator importante para a escolha dos pontos de coleta, foi a identificação dos usos preponderantes e mais restritivos da água subterrânea. Para a identificação destes usos, foi elaborado um questionário estruturado sendo o mesmo aplicado a um número representativo de usuários de água subterrânea na área de estudo. A região das duas microbacias estava parcialmente inserida em três bairros da cidade de Campina Grande - PB (Figura 2A), com uso e ocupação de solo diversos.

Com base nos dados de logradouros do Censo 2010 foi realizada a contagem do número de lotes em cada microbacia e estimada uma amostra estatisticamente significante da população da área de estudo. Sobre esta foi estendida uma malha quadriculada, sendo cada quadrícula de 100x100m, ao longo da qual foram aplicados cem questionários obrigatoriamente aos usuários de águas subterrâneas. A Figura 2B ilustra os pontos das microbacias em que foram aplicados os questionários.

Figura 2: Localização dos bairros nas microbacias estudadas em Campina Grande-PB.

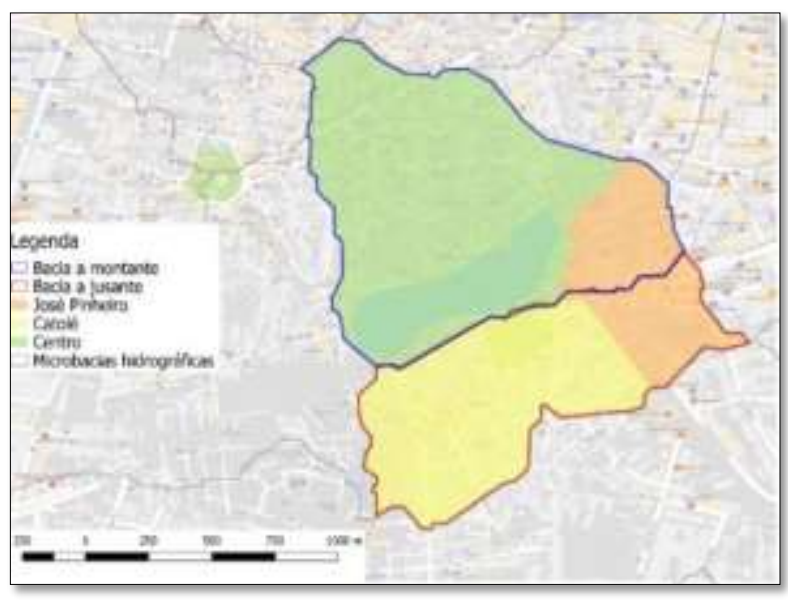

Fonte: Autoria própria.

Figura 3: Locais onde foram aplicados os questionários-PB.

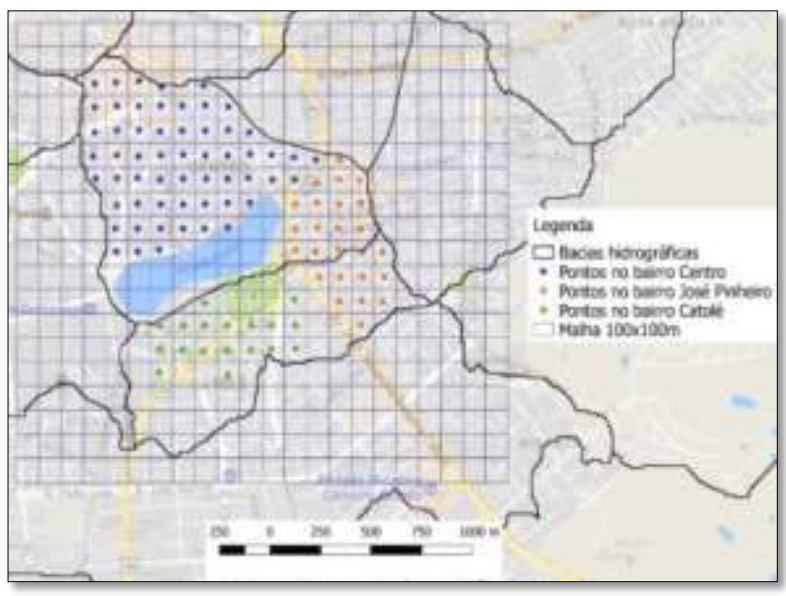

Fonte: Autoria própria. 
Os questionários foram elaborados no formato de perguntas e respostas, tendo sido perguntado como as pessoas utilizavam a água subterrânea, conforme as seguintes alternativas: limpeza de ambientes, rega de jardins, descarga de bacias sanitárias, preparação de alimentos, ingestão direta e outros usos. Caso a resposta incluísse preparação de alimentos ou ingestão direta, era pedido que o usuário relatasse a ocorrência de algum possível dano à saúde.

Após o estudo das respostas do questionário, foram escolhidos 5 poços (Tabela 2), dois na microbacia a montante e três na microbacia a jusante para realizar as análises físico-química.

$\mathrm{Na}$ Tabela 2 são descritas as principais informações técnicas sobre os poços tubulares nos pontos de coleta.

Tabela 2: Descrição dos pontos de coleta de amostras de água.

\begin{tabular}{cll}
\hline Ponto de Coleta & Ocupação & Microbacia \\
\hline P1 & Edifício residencial A (água bruta) & Montante \\
\hline P2 & Posto de gasolina (água bruta) & Jusante \\
\hline P3 & Empresa de prestação de serviços A (água bruta) & Jusante \\
\hline P4 & Lava jato (água bruta) & Jusante \\
\hline P5 & Empresa de prestação de serviços B (água bruta) & Montante \\
\hline
\end{tabular}

Fonte: Autoria própria.

Tabela 3: Informações técnicas sobre os pontos de coleta.

\begin{tabular}{llcccc}
\hline & & & & \multicolumn{2}{c}{ Coordenadas } \\
\cline { 5 - 6 } Poço & $\begin{array}{l}\text { Ano de } \\
\text { perfuração }\end{array}$ & $\begin{array}{l}\text { Vazão } \\
\left(\mathrm{m}^{3} / \mathrm{h}\right)\end{array}$ & $\begin{array}{c}\text { Profundidade } \\
\text { do poço }(\mathrm{m})\end{array}$ & Latitude & Longitude \\
\hline P1 & 2016 & 4 & 50 & $7^{\circ} 13^{\prime} 26^{\prime \prime}$ & $35^{\circ} 52^{\prime} 60^{\prime \prime}$ \\
\hline P2 & 2014 & 2 & 30 & $7^{\circ} 13^{\prime} 40^{\prime \prime}$ & $35^{\circ} 52^{\prime} 38^{\prime \prime}$ \\
\hline P3 & 2013 & 2 & 40 & $7^{\circ} 13^{\prime} 42^{\prime \prime}$ & $35^{\circ} 52^{\prime} 58^{\prime \prime}$ \\
\hline P4 & 2013 & 3 & 40 & $7^{\circ} 13^{\prime} 49^{\prime \prime}$ & $35^{\circ} 52^{\prime} 54^{\prime \prime}$ \\
\hline P5 & 2016 & 4 & 50 & $7^{\circ} 133^{\prime} 23 ”$ & $35^{\circ} 52^{\prime} 34^{\prime \prime}$ \\
\hline P6 & 2016 & 4 & 50 & $7^{\circ} 133^{\prime} 26^{\prime \prime}$ & $35^{\circ} 52^{\prime} 60^{\prime \prime}$ \\
\hline
\end{tabular}

Fonte: Autoria própria.

Foram realizadas 20 campanhas, com frequência semanal, entre os meses de fevereiro e agosto de 2017, pela manhã, totalizando 100 amostras analisadas. Durante a coleta de amostras foram utilizados luvas e álcool 70\% para a esterilização prévia das torneiras (ou registros).

Antes de iniciar o procedimento de coleta, as torneiras (registros) eram abertas por dois minutos, permitindo a descarga da água estagnada na tubulação. Em seguida, as amostras eram coletadas, sendo a temperatura, o único indicador verificado in loco. Todas as amostras para análises físico-químicas, foram analisadas em triplicata, no Laboratório de Saneamento da Universidade Federal de Campina Grande (UFCG). Já as análises microbiológicas, foram realizadas no Laboratório de Pesquisa em Ciências Ambientais (LAPECA) da Universidade Estadual da Paraíba (UEPB).

Todos os dados obtidos foram lançados em planilhas Excel, inspecionados quanto a ocorrência de valores extremos (outliers) e em seguida, determinados os parâmetros estatísticos descritivos dos diversos conjuntos amostrais, com ênfase para as médias.

Foi aplicada análise da variância (ANOVA) de fator único, com nível de significância 0,05 para verificar a existência $(\mathrm{p}<0,05)$, ou não $(\mathrm{p}>0,05)$, de diferenças significativas entre as médias dos diversos conjuntos amostrais de uma mesma 
variável, com o objetivo de comparar a qualidade das águas brutas provenientes dos poços tubulares. Por fim, foi ananlisado o coeficiente de Pearson, para identificar as possíveis correlações existentes entre os indicadores de qualidade de água.

\section{Resultados}

\subsection{Caracterização dos principais usos da água subterrânea}

A área de estudo foi caracterizada, de acordo com o uso e ocupação do solo, como predominantemente comercial, no entanto também é ocupada em menores proporções, por residências e por aparelhos de serviço público, o que é comum acontecer nas regiões centrais da maioria das cidades brasileira.

Foi identificado que a limpeza de ambientes sobressaiu-se como o uso preponderante de água subterrânea na área de estudo, uso menos restritivo que permite que a água subterrânea seja utilizada de modo mais expedito. Outros usos também foram identificados, como a utilização em descargas de aparelhos sanitários, rega de jardins, banho e outros, além da ingestão humana.

O uso para a ingestão humana triplicou com a implementação do racionamento de água na cidade de Campina Grande, ocorrendo, por outro lado, tendência de economia em usos como descarga, rega de jardins, banho e outros. O aumento do uso da ingestão humana com água subterrânea, pode ter ocorrido devido à falta de confiança da população na qualidade da água distribuída pelo serviço de abastecimento, no período do racionamento.

\subsection{Análise físico-quimica e microbiológica das águas subterrâneas}

Foram analisados em conjunto os indicadores de $\mathrm{pH}$ e temperatura das 104 amostras estudadas. Para a temperatura foram obtidos valores entre 23 a $29^{\circ} \mathrm{C}$, resultado esse que acompanhou a variação da temperatura atmosférica do ambiente externo. Já para o indicador $\mathrm{pH}$, todos os pontos analisados estavam em conformidade com o padrão estabelecido pela Portaria de Consolidação ${ }^{\circ} 5$ de 2017, com resultados que variaram de 6,4 a 7,9, sendo 74\% dessas amostras classificadas como água neutra.

O ponto P2 apresentou os maiores valores de dureza da série amostral (Figura 4), da mesma forma que os valores de condutividade elétrica, indicando uma maior concentração de sais e uma provável influência de fatores, como menor profundidade e menor vazão. O ponto P4, situado a uma maior distância linear do açude eutrofizado, apresentou o menor valor da série amostral do indicador dureza.

Figura 4: Variação temporal de dureza total em águas subterrâneas da área de estudo.

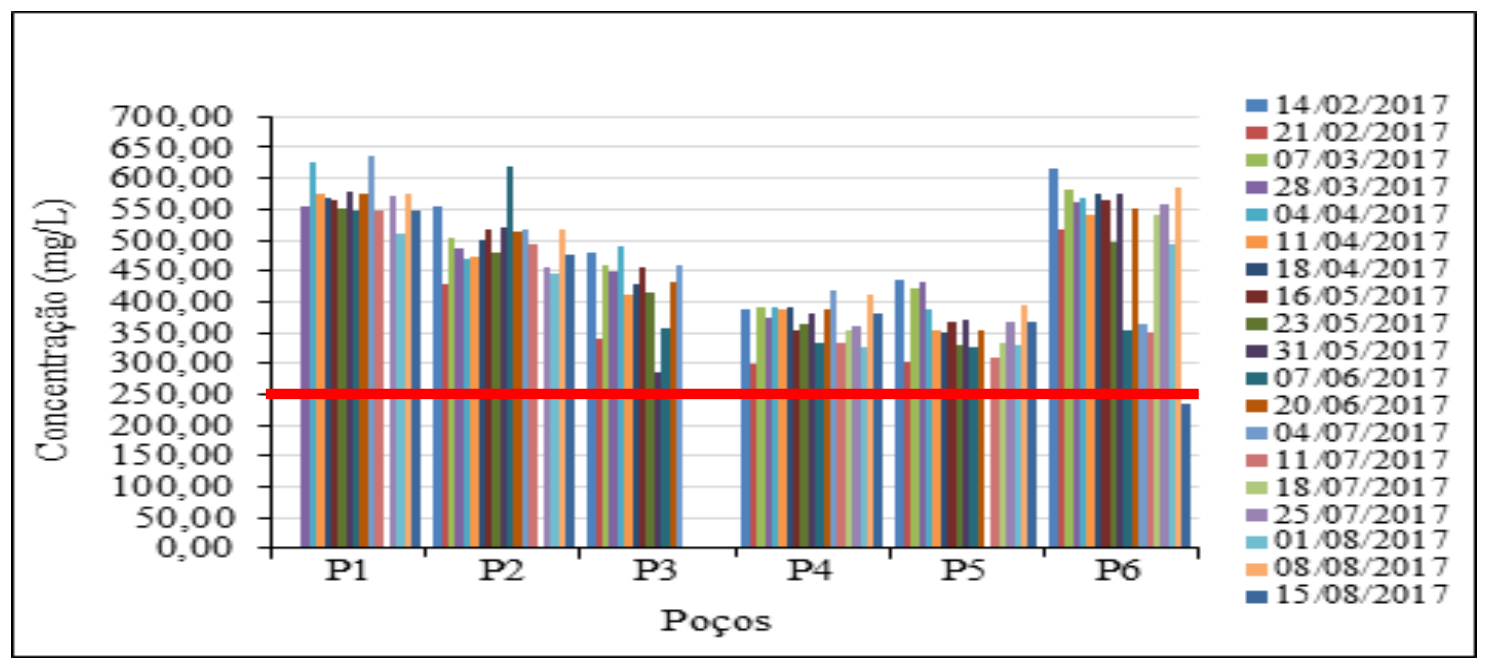

Fonte: Autoria própria. 
Nas amostras analisadas, a concentração de cloretos variou de 303 a $634 \mathrm{mgCl}^{-} / \mathrm{L}$ (Figura 5), excedendo, em todas, o que é estabelecido (250 mg Cl-/L) pela Resolução CONAMA 396/2008 e pela Portaria de Consolidação nº 5 de 2017 , demonstrando uma possível influência na qualidade da água pela hidrogeologia local e pela contaminação por ação antrópica.

Figura 5: Variação temporal de cloreto em águas subterrâneas da área de estudo.

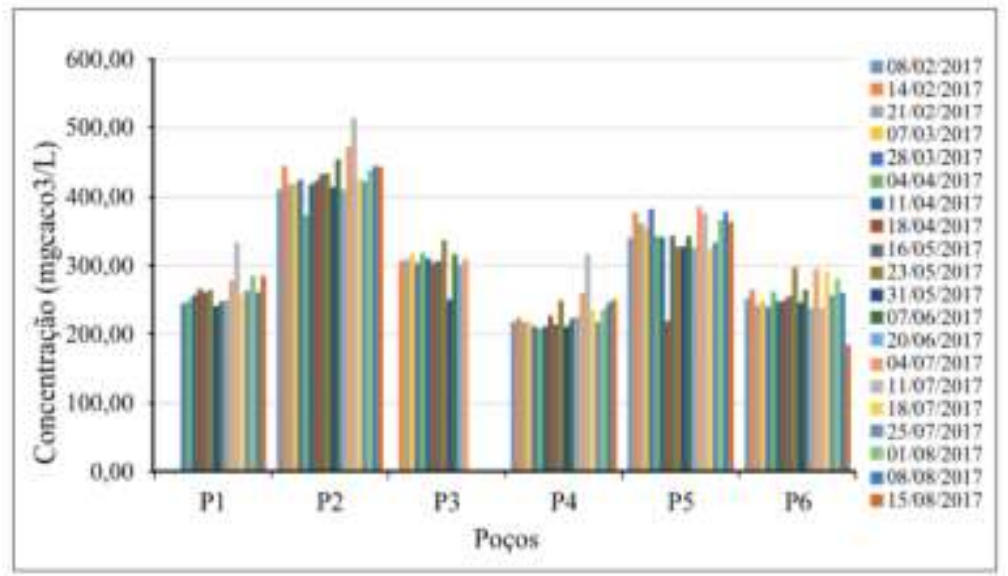

Fonte: Autoria própria.

Para o fluoreto, o limite máximo em água potável, é de 1,5 mgF-/L, considerado pela Organização Mundial de Saúde (WHO, 2006), também adotado pela Portaria de Consolidação n ${ }^{\circ}$ 5/ 2017 do Ministério da Saúde e pela Resolução CONAMA 396/2008, foi superado em todos os pontos, em mais da metade das amostragens (Figura 7). A ingestão contínua de águas com concentrações elevadas pode causar fluorose esqueletal ou dentária (Ezaki et al., 2015).

Os valores de fluoreto nas amostras analisadas variaram de 1 a 3,3 mgF-/L, sendo os pontos $\mathrm{P} 3$ e P4, que pertencem à microbacia a jusante e apresentam a mesma profundidade, os maiores valores da série. O ponto P5, da microbacia a montante, apresentou os menores resultados da série amostral. Porém, os resultados médios de todas as amostras excederam o valor máximo permitido de fluoreto para o consumo humano, estipulado pela Portaria de Consolidação n 5 de 2017 .Figura 6 Variação temporal de fluoreto em águas subterrâneas da área de estudo

Figura 6: Variação temporal de fluoreto em águas subterrâneas da área de estudo.

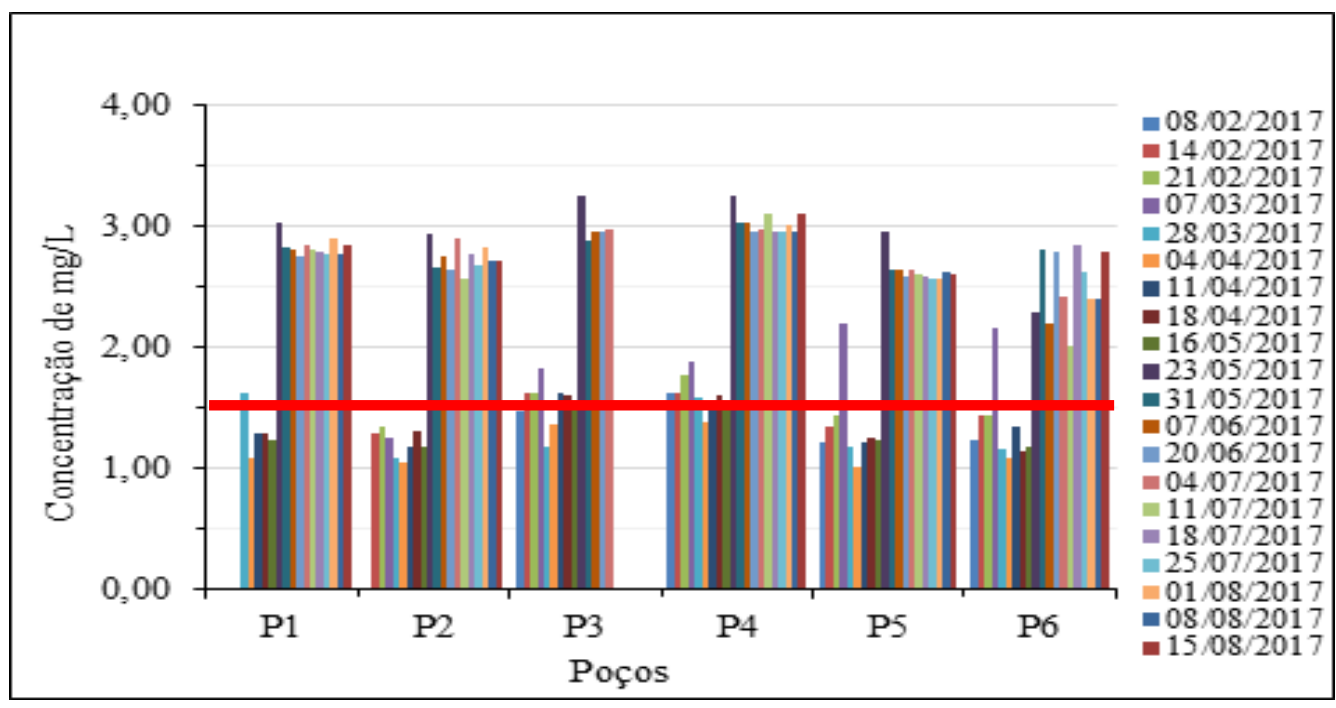

Fonte: Autoria própria. 
Os valores do nitrato das amostras analisadas (Figura 7) foram abaixo do valor máximo permitido (VMP) de $10 \mathrm{mg}$ N-NO3-/L para consumo humano, estipulado pela Resolução CONAMA 396/2008 e pela Portaria de Consolidação $n^{\circ} 5$ de 2017, sendo assim, de acordo com esse indicador, essas águas subterrâneas poderiam ser destinadas ao consumo humano.

Para as concentrações de ferro durante o período da pesquisa estiveram abaixo dos limites de detecção do método (LDM) e de quantificação praticável (LQP), de acordo com a Resolução CONAMA n 396/2008, sendo, por isso, considerado ausente.

Os valores de sólidos dissolvidos totais (com exceção do ponto P6) variaram de 1107 a $1889 \mathrm{mg} / \mathrm{L}$. Todas as águas brutas analisadas foram consideradas impróprias para consumo humano de acordo com os valores máximos permitidos.

Figura 7: Variação temporal de fluoreto em águas subterrâneas da área de estudo.

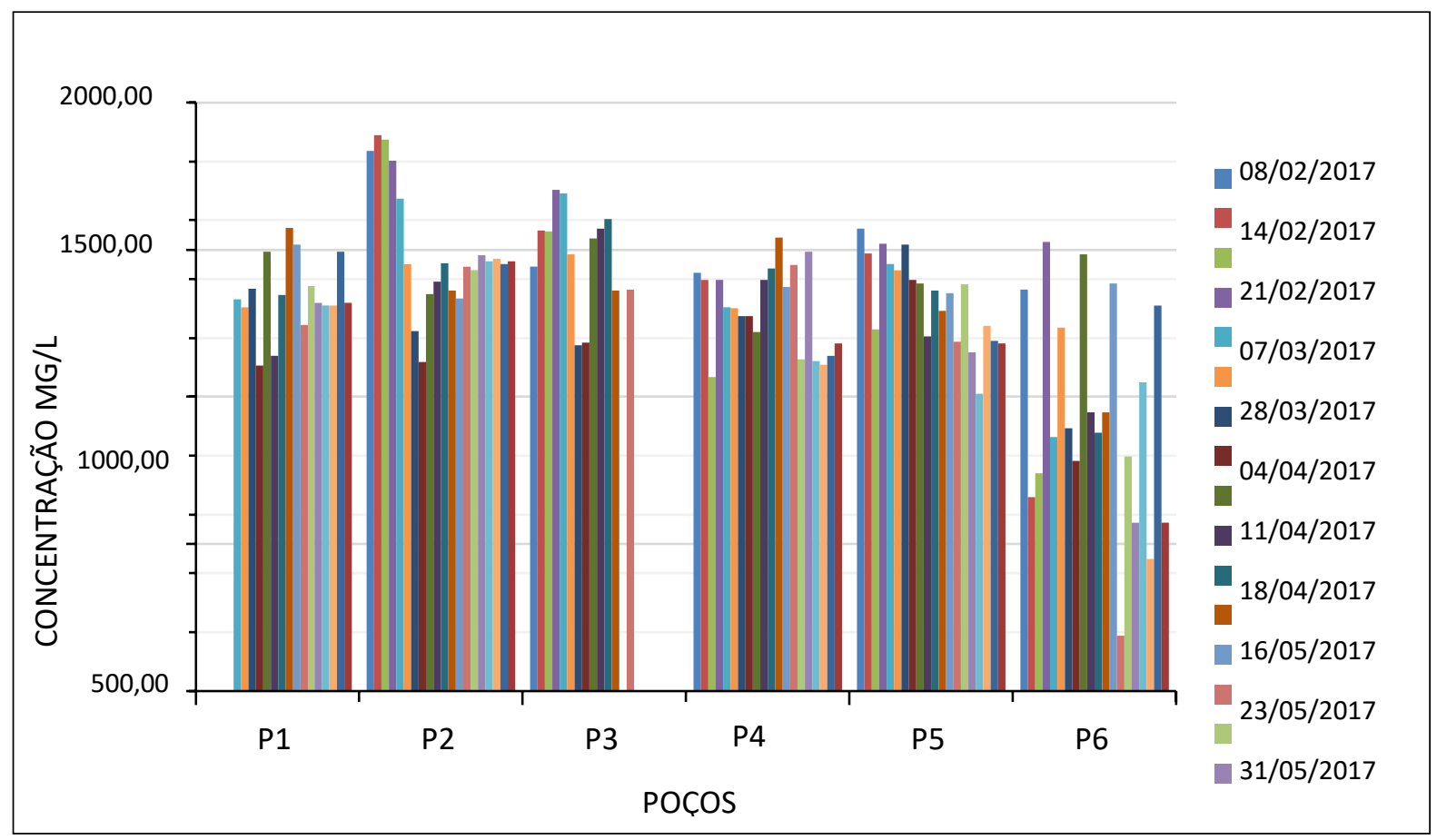

Fonte: Autoria própria.

\subsection{Análises microbiológicas}

Todas as amostras dos pontos P2, P3 e P4, 95\% das amostras do ponto P5 e 68,75\% das amostras do ponto P1 foram positivas para a presença de coliformes totais.

Os pontos P2 e P3 estão ambos localizados na microbacia a jusante e a uma distância de menos de $50 \mathrm{~m}$ do açude eutrofizado, também considerado como fonte de contaminação das águas subterrâneas. A presença de fossas sépticas próximas aos poços tubulares também seria uma possível causa de positividade de coliformes totais nas águas subterrâneas.

Nas análises de Escherichia coli, o ponto P1 apresentou a menor presença desse indicador, com apenas 12,5\% de positividade nos testes. Já o ponto $\mathrm{P} 3$ apresentou $100 \%$ de presença de $E$. coli em suas amostras, indicando contaminação fecal contínua e recente.

\subsection{Análise de variância (ANOVA)}

Os resultados da ANOVA referentes a comparação entre as águas brutas, mostraram que existem diferenças significativas nos conjuntos amostrais em todos os pontos analisados, exceto para o indicador fluoreto. 
Figura 8: Agrupamento dos dados de acordo com o método gráfico de Hochberg GT-2.

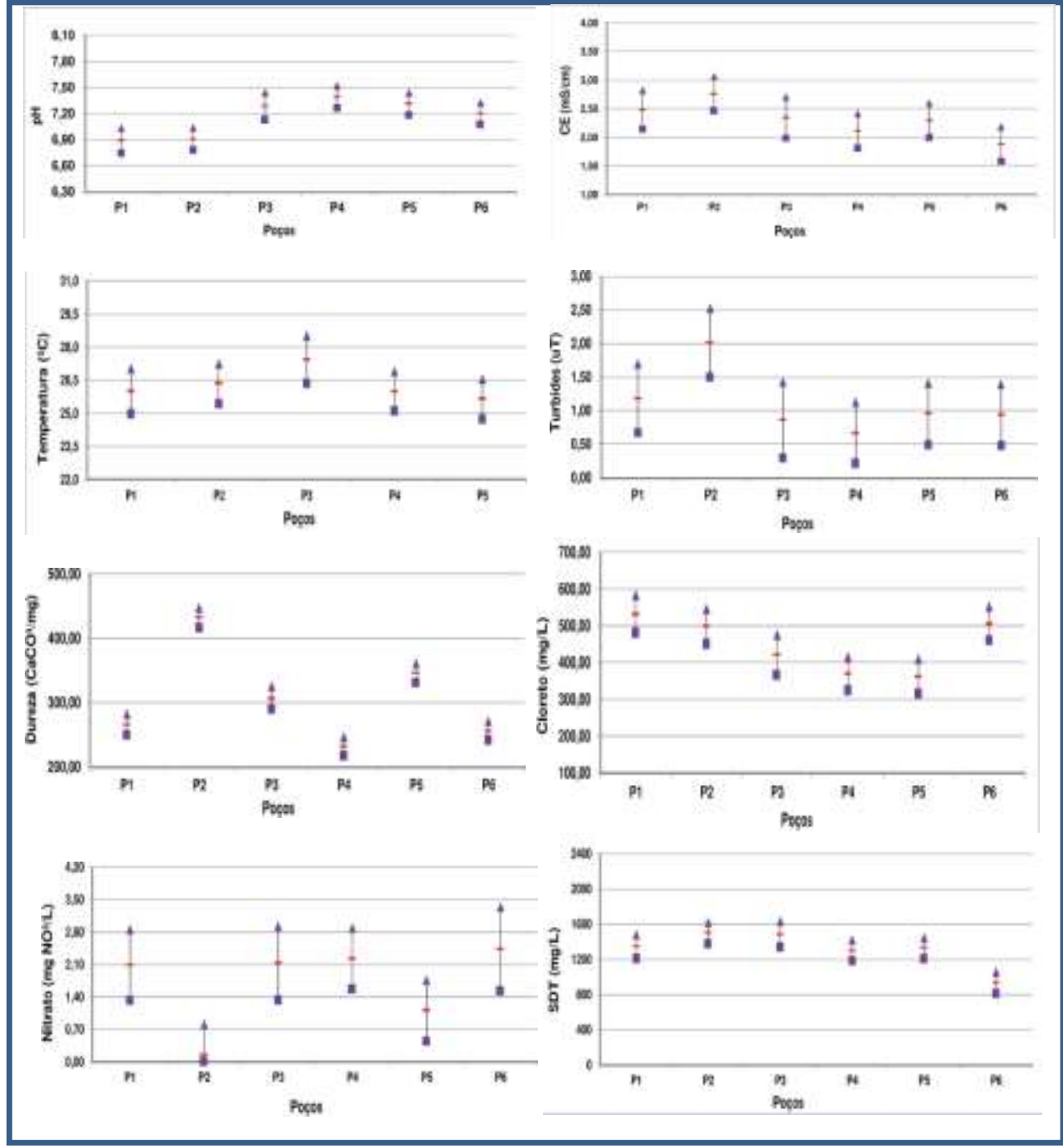

Fonte: Autoria própria.

Para identificar quais eram os dados que possuíam diferença estatisticamente significante, foi aplicado o método gráfico de Hochberg GT-2 para ilustrar o agrupamento dos dados, como está disposto na Figura 8.

No parâmetro pH houve a formação de dois grupos, sendo P1 e P2 valores aproximados e P3, P4, P5 e P6 a formação do segundo grupo. Nos demais indicadores, exceto o fluoreto, houveram diferenças estatisticamente significante. Analisando os parâmetros CE, turbidez, dureza total e nitrato o ponto P2 distou do agrupamento dos demais pontos. Já nos resultados de sólidos totais e cloreto houve diferenças estatisticamente significante, porém nenhum agrupamento aparente.

\subsection{Determinação dos coeficientes de correlação de Pearson}

Foram determinados os coeficientes de correlação de Pearson (Tabela 4) entre os conjuntos de dados das variáveis determinadas nos poços. Os coeficientes de correlação estatisticamente significativos, a um nível de significância $\alpha=0,05$, grafados em negrito, apresentam módulos iguais ou superiores ao coeficiente de correlação crítico. Dos 36 coeficientes, 14 são estatisticamente significantes, sendo 7 positivos e 7 negativos, indicando, em todos os casos, a degradação da qualidade da água. Dentre os primeiros, destacam-se os coeficientes entre sólidos dissolvidos totais (SDT), CE e Dureza e entre estes dois últimos e turbidez. Das correlações negativas destacam-se aqueles referentes aos indicadores nitrato, CE, turbidez, dureza e 
SDT. O fluoreto foi o único que não apresentou nenhuma correlação significativa (positiva ou negativa) entre os indicadores analisados.

Tabela 4: Correlação de Pearson dos indicadores analisados em águas subterrâneas na cidade de Campina Grande-PB.

\begin{tabular}{lllllllll}
\hline Indicador & Temperatura & $\mathbf{p H}$ & $\mathbf{C E}$ & Turbidez & $\begin{array}{l}\text { Durez } \\
\mathbf{a}\end{array}$ & $\begin{array}{l}\text { Cloret } \\
\mathbf{0}\end{array}$ & $\begin{array}{l}\text { Fluoret } \\
\mathbf{0}\end{array}$ & Nitrato \\
\hline $\mathbf{p H}$ & 0,009 & & & & & & & \\
$\mathbf{C E}$ & 0,431 & $\mathbf{- 0 , 6 8 0}$ & & & & & & \\
Turbidez & 0,074 & $\mathbf{- 0 , 8 0 7}$ & $\mathbf{0 , 8 0 0}$ & & & & & \\
Dureza & 0,225 & $-0,431$ & $\mathbf{0 , 7 6 6}$ & $\mathbf{0 , 8 3 2}$ & & & & \\
Cloreto & $-0,089$ & $\mathbf{- 0 , 8 5 5}$ & 0,251 & $\mathbf{0 , 5 5 0}$ & 0,090 & & & \\
Fluoreto & $-0,035$ & $-0,092$ & 0,124 & $-0,183$ & $-0,454$ & $-0,059$ & & \\
Nitrato & $-0,035$ & 0,424 & $\mathbf{- 0 , 7 6 7}$ & $\mathbf{- 0 , 8 2 9}$ & $\mathbf{- 0 , 9 5 2}$ & $-0,015$ & 0,248 & \\
SDT & $\mathbf{0 , 7 1 7}$ & $-0,229$ & $\mathbf{0 , 8 4 3}$ & 0,405 & $\mathbf{0 , 5 6 5}$ & $-0,198$ & 0,231 & $\mathbf{- 0 , 5 4 6}$ \\
\hline
\end{tabular}

Nota: $\mathrm{r}$ crítico $=0,4725$ foi determinado para o nível de significância $\alpha$ de 0,05 e o to,05 de Student. Fonte: Autoria própria.

\subsection{Discussão}

Os fatores, distância dos poços ao açude eutrofizado, profundidade, vazão de bombeamento, localização em diferentes microbacias, proximidade com pontos de contaminação, foram selecionados para relacionar com características físicoquímicas e microbiológicas das águas subterrâneas analisadas.

Foi verificado com base nos resultados do ponto P2, que tem a menor profundidade de perfuração e a menor vazão disponível para bombeamento, que os valores de CE, turbidez, dureza e SDT foram os maiores da série amostral analisada, sendo possível levantar a hipótese de que quanto mais rasos e com menor vazão disponível para bombeamento, os poços tubulares, estariam mais susceptíveis à contaminação.

O ponto P4, com a maior distância linear com relação ao Açude Velho, apresentou os menores resultados dos indicadores CE, dureza e SDT, indicando a importância da maior ou menor distância do poço ao corpo hídrico contaminado sobre a degradação da qualidade da água.

De fato, não foi observada uma relação bem definida dos dados com fatores como distância ao açude eutrofizado, profundidade dos poços e vazão disponível para bombeamento, sendo isso uma característica típica de aquíferos cristalinos. Também, não foi observada uma correlação da qualidade da água subterrânea com o posicionamento dos poços nas microbacias a jusante e a montante, confirmando mais uma vez, que cada poço perfurado em um aquífero cristalino possui suas características próprias. No entanto a identificação dos usos da água subterrânea na área de estudo e a caracterização da sua qualidade físico-química e microbiológica foi de vital importância para diminuir o risco desses usos para a população.

\section{Considerações Finais}

A pesquisa identificou que o uso preponderante das águas subterrâneas, na área de estudo, foi a limpeza de ambientes, porém outros usos como descarga em aparelhos sanitários, rega de jardins, banho e a ingestão humana também são feitos. Os usuários que foram entrevistados, utilizavam como tratamento doméstico das águas subterrâneas a desinfecção com cloro e a fervura, no entanto, eles relataram nunca ter sentido nenhum desconforto à saúde devido à ingestão dessas águas.

A água subterrânea analisada na cidade de Campina Grande não atende aos padrões de potabilidade estabelecidos pela Portaria de Consolidação $n^{\circ}$ 5/2017, particularmente os padrões para os indicadores cloreto, fluoreto e sólidos dissolvidos 
totais. Em relação aos indicadores microbiológicos (determinação de presença/ausência de coliformes totais e Escherichia coli) a situação é semelhante, pois foi constatado que, em todos os pontos, não houve conformidade, sendo essa violação atribuída à contaminação do lençol freático por fontes pontuais, como fossas sépticas, canais de drenagem de águas pluviais com o lançamento de esgotos e corpos hídricos contaminados.

Vale salientar que, caso essas águas subterrâneas sejam ingeridas poderão ensejar risco à saúde da população. Por isso como sugestão para estudos futuros, para que se torne própria para o consumo humano, é necessário haver estudos complementares que indiquem um método de tratamento de água eficiente e simples, detalhando volume e dosagem de agentes desinfetantes, para que a população possa fazer melhor uso dessas águas.

\section{Referências}

Aith F. M. A., \& Rothbarth R. O estatuto jurídico das águas no Brasil. Revista estudos avançados, 29.

Grisi, L. Cresce o número de perfuração de poços em Campina Grande. Jornal da Paraíba, Campina Grande-PB 28 de setembro de 2016.

APHA, AWWA, WEF. Standard methods for the examination of water and wastewater. (22a ed.) 2012.

Bastos A. G. L,, Alves F. M., Oliveira J. L., \& Costa C. T. F. Avaliação espacial da contaminação das águas subterrâneas proveniente dos postos de revenda de combustíveis no município de juazeiro do norte - CE. In: XVII Congresso Brasileiro de Águas Subterrâneas, 2012.

Brasil, Ministério da Saúde. Portaria de Consolidação no 5/2017, de 12 dezembro de 2011. Dispõe sobre os procedimentos de controle de vigilância da qualidade da água para consumo humano e seu padrão de potabilidade. Diário Oficial da União, Brasília, Seção 1, p.30, 12 Dez. 2011.

CONAMA - Conselho Nacional do Meio Ambiente. Resolução nº ${ }^{\circ}$ 396, de 03 de abril de 2008. Dispõe sobre a classificação e diretrizes ambientais para o seu enquadramento. CONAMA, 2008.

Coelho V. M. T., \& Duarte U. (2017). Perímetros de proteção para fontes naturais de águas Minerais. In: XII Congresso brasileiro de águas subterrâneas, Anais, São Paulo-SP.

Daneluz, D., \& Tessaro D. Padrão físico-químico e microbiológico da água de nascentes e poços rasos de propriedades rurais da região sudoeste do Paraná. Scientific communication, 82(1).

Ezaki, S. , Hypolito, R., Pérez, A., Moschini, F. A., Moura, C. L., \& Pugas, M. S. Avaliação da ocorrência de íon fluoreto nas águas subterrâneas dos aquíferos tubarão e cristalino, região de salto (SP). I Congresso Internacional de Meio Ambiente Subterrâneo, São Paulo-SP, 2015.

IBGE. (2010). Instituto Brasileiro de Geografia e Estatística. Pesquisa Nacional de Saneamento Básico 2008.

Karim M. M., Amr M. M., \& Ahmed E. H. (2018). Groundwater sustainability: opportunity out of threat. Groundwater For Sustainable Development.

Lisboa, E. G., Carvalho, J. M. C. M., \& Mendes, R. L. R. O Uso da Geoestatística na Avaliação dos Parâmetros Hidrogeológicos para Compor o Mapa de Vulnerabilidade Intrínseca de Aquíferos. Revista Brasileira de Recursos Hídricos, 21(1).

Marengo O. J. A. Mudanças climáticas globais e seus efeitos sobre a biodiversidade, caracterização do clima atual e definição das alterações climáticas para o território brasileiro ao longo do século XXI (segunda edição). Brasília: Ministério do Meio Ambiente, 1.214.

Oliveira, H. A., Bezerra, H. N., Araújo, J. M. S., \& Tavares, L. A. F. Qualidade de águas de poços dos assentamentos da Chapada do Apodi-RN para o uso na agricultura, 29(1).

Razzolini M. T. P., Günther W. M. R., Rocha S. M., \& Luca H. D., Cardoso M. Impactos na saúde das deficiências de acesso a água. Revista saúde e sociedade, 17(1),.21-32.

Rodrigues M.V. C., Giraldi E. H., Santos M. M., Costanzi R. N., \& Celligoi A. (2014). Avaliação preliminar da qualidade das águas subterrâneas e superficiais na área de entorno do antigo lixão no município de Rolândia-PR. In. XVIII Congresso Brasileiro de Águas Subterrâneas.

Salgado, J. P. (2016). Influência do lançamento de esgotos na qualidade das águas do aquífero aluvial do rio Sucurú, no município de Sumé - PB. Dissertação (Mestrado em Engenharia Civil e Ambiental) Universidade Federal de Campina Grande, Programa de Pós- Graduação em Engenharia Civil e Ambiental. Campina Grande, Paraíba.

Santos V. R. L., Campos C. A., Xavier F. F., Oliveira M. C. J., \& Alves W. F. (2014). Monitoramento da qualidade da água subterrânea na área do cemitério de Taguatinga - DF. XVIII Congresso Brasileiro de Águas Subterrâneas.

Shiklomanov, I. A., \& Rodda, J. C. (2014). World water resources at the beginning of the $21^{\text {st }}$ century.

Silva, C. C. N., Medeiro, W. E., Sá, E. F. J., \& Xavier Neto, P. (2004). Resistivity and ground-penetrating radar images of fractures in a crystalline aquifer: a case study in Caiçara farm-NE Brazil. Journal of Applied Geophysics. 56(4), 295-307

Sotomayor, D., Wiliams R. G., Lowrance R., Bosch D. D., Benham E., Dieppa A., \& Hubbard R. Hydrology and water quality of a field and riparian buffer adjacente to a mangrove wetland in Jobos Bay watershed, Puerto Rico. Ecological Engineering, 56. 
Research, Society and Development, v. 10, n. 14, e164101420168, 2021

(CC BY 4.0) | ISSN 2525-3409 | DOI: http://dx.doi.org/10.33448/rsd-v10i14.20168

Sreedevi P. D., Ahmed S., Made B., Ledoux E., \& Gandolfi J. M. (2006). Association of hydrogeological factors in temporal variations of fluoride concentration in a crystalline aquifer in India. National Geophysical Research, 11.

Tamiru, A, A. (2011). Provenance of groundwater in the crystalline aquifer of Johannesburg area, South Africa. International Journal of the Physical Sciences. $6(1), 98-111$.

Torquato A. L. (2017). Estimativa do assoreamento e avaliação da qualidade das águas do açude velho na cidade de campina grande/PB. 2017.102 F. Dissertação (Mestrado em Engenharia civil e ambiental)- Universidade Federal de Campina Grande. Campina Grande.

Tsuyuguchi. B. B. (2015). Macrodrenagem e ocupação do solo no município de Campina Grande: caracterização, simulação e análises sistêmicas. Dissertação (Mestrado em Engenharia Civil e Ambiental) Universidade Federal de Campina Grande, Programa de Pós- Graduação em Engenharia Civil e Ambiental. Campina Grande, Paraíba.

UNESCO International Hydrology Series (2014).

WHO. (2006).World Health Organization. Guidelines for drinking-water quality. WHO.

WHO. (2015). World Health Organization. Guidelines for drinking-water quality. WHO. (4a ed.). 